\section{The management of dental anxiety: time for a sense of proportion?}

\author{
T. Newton, ${ }^{1}$ K. Asimakopoulou, ${ }^{2}$ B. Daly, ${ }^{3}$ S. Scambler ${ }^{4}$ and S. Scott ${ }^{5}$
}

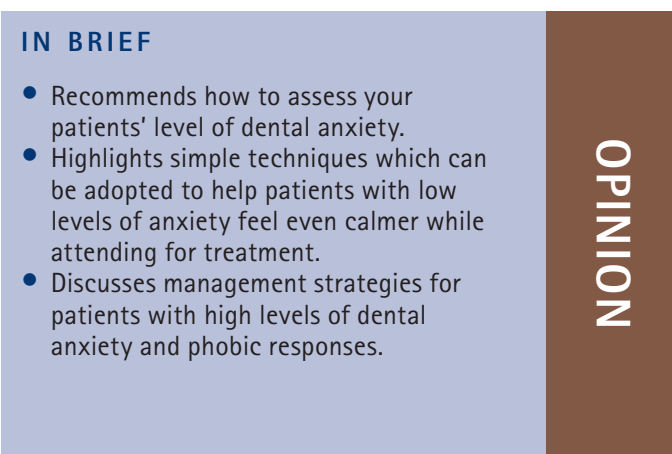

\begin{abstract}
Dental anxiety and fear are common and potentially problematic, both for the patient and for the dental team in managing such patients. Furthermore, dental fear still presents a major barrier to the uptake of dental treatment. This article will take as its premise an assumption that anxiety manifests at different levels and that consequently management of dental anxiety involves both assessment and proportionate intervention. Methods for undertaking both assessment and management are outlined.
\end{abstract}

\section{INTRODUCTION}

Fear of dental treatment and anxiety about dental procedures are prevalent and have an impact on the quality of life and the quality of dental treatment performed - both in terms of limiting attendance for treatment and in the nature of the dental treatment likely to be performed. ${ }^{1}$ Delay in seeking treatment as a result of dental anxiety often means that conservative treatment options are not viable. Furthermore, until recently, services for people with dental fear and anxiety have largely focused on extreme levels of dental fear (dental phobia) and adopted a pharmacological management strategy. The development of the Index of Sedation $\mathrm{Need}^{2}$ provides guidance on those situations in which sedation is appropriate in the management of individuals with high levels of dental anxiety, but fails to address the needs of individuals who are anxious about treatment but not sufficiently so to warrant the diagnosis of a phobic level of fear.

In this article we take as a key premise the view that all patients may have some level of anxiety about their treatment. On the basis of this we propose that it is

${ }^{1 *-5}$ King's College London Dental Institute, Health Psychology Service

*Correspondence to: Professor Tim Newton Email: tim.newton@kcl.ac.uk

\section{Refereed Paper}

Accepted 25 June 2012

DOI: $10.1038 /$ sj.bdj.2012.830

${ }^{\oplus}$ British Dental Journal 2012; 213: 271-274

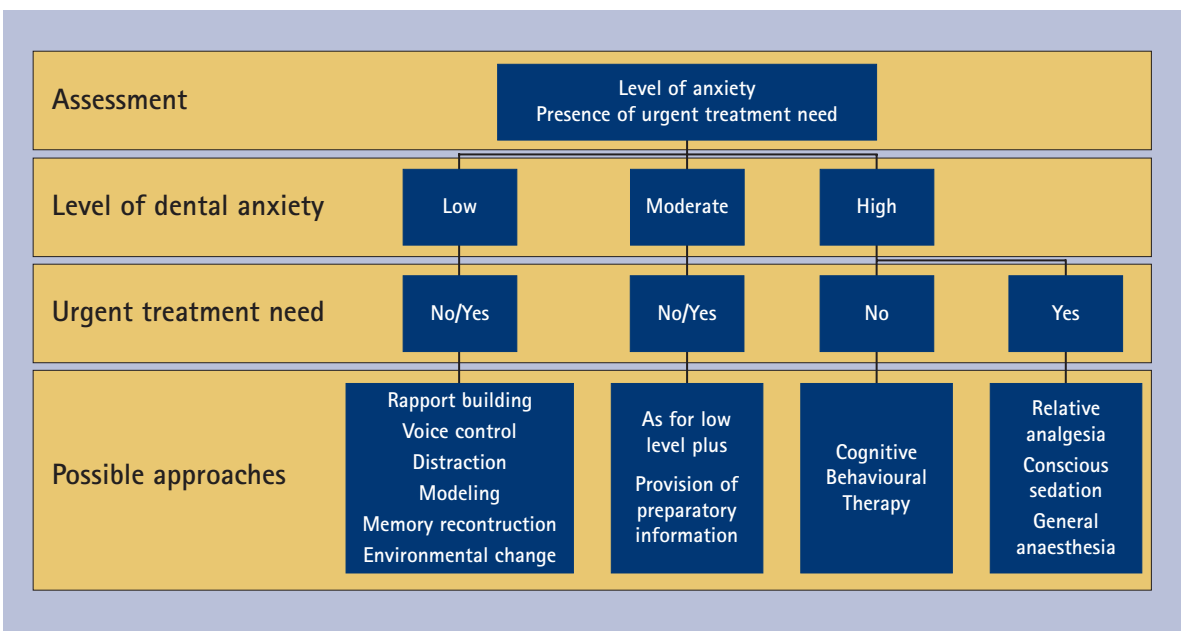

Fig. 1 An outline of approaches to the management of dental anxiety, based on the initial assessment of the level of dental anxiety, followed by proportionate intervention

essential to the clinical management of the patient that the dental team assesses the patient's level of anxiety and intervenes proportionately. Patients with low levels of dental anxiety may require only low level interventions involving enhancing the environment and reducing the degree of uncertainty involved in treatment. Those patients with moderate levels of dental anxiety may require more intensive interventions, such as the provision of information on coping strategies. Finally for the phobic dental patient, the complementary use of pharmacological and psychological approaches (most notably cognitive behavioural therapy) will be discussed. Figure 1 provides an overview of possible management strategies, according to level of dental anxiety.

\section{ASSESSMENT OF DENTAL ANXIETY}

There are numerous instruments available for the assessment of dental anxiety, both in children and adults. ${ }^{3,4}$ The most recent Adult Dental Health Survey adopted the Modified Dental Anxiety Scale ${ }^{5}$ (MDAS, see http://www.st-andrews.ac.uk/dentalanxiety/), a five item scale that is reliable and quick to administer. It has cut-offs for mild, moderate, and phobic levels of anxiety. ${ }^{6}$ While there are more comprehensive measures which allow for the more specific identification of aspects of the individual's dental anxiety, the MDAS provides a simple, easy-to-use screening tool. It has been found to be acceptable both to patients and the dental team. ${ }^{7,8}$ A version is also available for use with children ${ }^{9}$ (Modified Child Dental Anxiety Scale, MCDAS). 


\section{INTERVENTIONS FOR INDIVIDUALS WITH LOW LEVELS OF ANXIETY}

Given the relationship between the development of dental anxiety and the experience of traumatic dental treatment, and further the role of latent inhibition in ameliorating the impact of negative events, ${ }^{10}$ dental anxiety may be prevented by the avoidance of negative experiences and the promotion of positive experiences for children attending the dental surgery. Examples of such approaches could include encouraging a warm and welcoming childfriendly environment (some examples of how such an approach could be adopted are given below), the provision of acclimatisation visits for children where no invasive dental treatment is performed, and the use of fluoride supplements to inhibit caries and thus prevent invasive treatment. ${ }^{11}$ However, there is currently little evidence to confirm or refute the effectiveness of such an approach in preventing future dental anxiety.

For children attending with low levels of dental fear, evidence-based approaches that can be adopted include:

- Rapport building: for example the use of a magic trick. Peretz and Gluck ${ }^{12}$ used a magic trick to encourage children who on a previous visit to the dental surgery had refused to enter the dental surgery, to sit in the dental chair and have a radiograph. The simple use of the trick increased cooperation when compared to no intervention or the use of tell-show-do. It is unclear the mechanism of action for this technique but one element may be the rapport building involved

- Voice control: there are a number of studies to demonstrate that children respond best to a moderately loud voice with a deep tone. Greenbaum et al. ${ }^{13}$ studied the effect of the loudness of the dentist's voice on the disruptive behaviour of 40 children aged between 3 and 7 years. They found that issuing commands in a loud voice were more effective in reducing disruptive behaviour than using a normal voice level. The children who received loud commands reported finding the interaction more pleasurable than the normal voice level group

- Distraction: several types of distraction have been reported in the literature, including the use of video-taped cartoons, audio-taped stories and video games. Distraction techniques have been found to be as effective as relaxation-based techniques, and superior to no intervention. Audiotaped distractions are more effective than video-taped, possibly since they allow children to close their eyes and hence avoid the feared stimulus. ${ }^{14}$ The most significant reductions in anxiety related behaviour are found when the distracting material is made contingent on cooperative behaviour. Children who were shown cartoons which were stopped if they became uncooperative, showed less than half the levels of disruptive behaviour in comparison to children who were shown cartoons regardless of their behaviour. ${ }^{15}$ Here the effectiveness of the technique may be the result of the rewarding properties of the cartoons

- Modeling: modeling has been used extensively with children and is generally most effective if the observed child is similar in age, gender and level of dental anxiety to the child watching, if the child enters and leaves the surgery without adverse consequences, and if the child is seen to be rewarded for non-anxious behaviour. ${ }^{16}$ With the increasing availability of low cost video cameras and the widespread ability to view video on handheld formats, practices and practitioners could consider providing modeling via websites to show successful patient management

- Memory reconstruction: Pickrell et al. ${ }^{17}$ designed an intervention based on an understanding of the processes of human memory, which involved using positive images to help children reconstruct their memory of dental treatment. The intervention comprised four components. Firstly the visual component, pictures taken previously of the child smiling during the dental procedure were shown back to the child as a visual reminder about the dental experience. Secondly verbalisation, the child was asked how he/she would explain to the parents how well they handled the dental appointment. Thirdly the provision of a 'concrete example', the child was asked to recall a good example of their improved behaviour in the dental setting. This would lead to the fourth component, the sense of accomplishment. The distinctive feature of this intervention is the fact that it is employed after the dental procedure and seeks to tackle the cognitions around the dental experience

- Environmental change: three studies have sought to make the dental environment more attractive to children attending the dental surgery. ${ }^{18-20}$. For example, Fox and Newton ${ }^{20}$ reported a decreased state of anxiety following exposure to positive images of the dental surgery as opposed to neutral images before treatment. Based upon theories of social learning and cognitive reconstruction, the authors aimed to provide positive cognitions concerning a trip to the dental clinic, in nonphobic children.

For adult patients with low levels of dental fear the following approaches to providing an anxiety reducing environment can be suggested:

- Enhancing the sense of control: uncertainty is anxiety provoking, and can be reduced by providing preparatory information and by enhancing an individuals sense of control over the situation. One widely used technique to do this is the stop signal, which has been shown to be effective in dental settings and a wide variety of other medical settings ${ }^{16,21}$

- Cognitive distraction: the patient is encouraged to think about something other than the dental situation. This has been shown to be effective in adults. Evidence suggests that the technique is only useful if the patient is informed that it is likely to reduce anxiety ${ }^{22}$

- Environmental change: the smell of lavender in the dental waiting area has been shown to reduce immediate fear about treatment, but not the underlying cognitions about dental treatment in adults. ${ }^{23}$ This demonstrates the importance of considering both the immediate response to the setting and more 
long-term cognitions underlying the patient's reaction to dental treatment.

\section{INTERVENTIONS FOR INDIVIDUALS WITH MODERATE LEVELS OF ANXIETY}

The adoption of all the approaches identified for individuals with low levels of anxiety will help to create a calm and welcoming environment. In addition, individuals with moderate levels of dental anxiety may benefit from the provision of preparatory information. Reviews of the effectiveness of preparatory information suggest that information on three aspects of the treatment are important:

- Information about what will happen (procedural information)

- Information about what sensations the individual will experience (sensory information)

- Information about what the individual can do to cope with the situation (coping information).

An example might be the giving of a local anaesthetic injection. Information can be given about the sensations the individual will experience - for example while there is no sensation in the injected area, the patient will still be able to feel vibration and pressure. Typically this takes two to five minutes to start and lasts up to two hours. When the injection fades, the sensation is similar to 'pins and needles', which the patient will have experienced.

There is some limited evidence that the amount of information given should be tailored to the characteristics of the individual, most notably their locus of control. Individuals with an internal locus of control show greater benefit in terms of anxiety reduction from the provision of information, than individuals with a more external locus of control. ${ }^{24}$

\section{INTERVENTIONS FOR INDIVIDUALS WITH HIGH LEVELS OF ANXIETY}

\section{Pharmacological management}

Pharmacological approaches to the management of patients with dental phobia are well established, including relative analgesia, conscious sedation and general anaesthesia. There is an ongoing need for such services when individuals delay treatment to the point where they are in severe pain or have otherwise compromised their oral health. However, in general, pharmacological approaches are seen as less acceptable in the management of dental fear when compared to psychological techniques both by individuals with extreme dental fear and members of the general public. ${ }^{25,26}$

\section{Cognitive behavioural therapy}

Cognitive behaviour therapy (CBT) is an example of a brief psychological therapy with proven effectiveness. It is a synthesis of behaviour therapy and cognitive therapy and uses both behaviour modification techniques and cognitive restructuring procedures to change maladaptive beliefs and behaviours. ${ }^{27}$ Behavioural aspects of CBT include learning relaxation skills, conducting mini-experiments and systematic desensitisation (constructing a hierarchy of situations that elicit varying and increasing degrees of anxiety or fear and then progressing through the hierarchy in a relaxed, non-anxious manner). Cognitive therapy ${ }^{28}$ on the other hand, is based primarily in the analysis of people's cognitions (for example, thoughts, beliefs, interpretations). The idea here is that the way people think about events plays a central role in their emotions (for example, anxiety) and physiological responses (for example, excessive perspiration) pave the way to establishing and maintaining unhelpful behaviours such as avoidance. ${ }^{29}$ Cognitive therapy therefore, aims to facilitate a new understanding (cognitive restructuring) that the feared stimuli are unlikely to be dangerous and in turn that avoidance or other safety behaviours are not required. ${ }^{30}$

An important principle underlying CBT is its focus on the 'here and now' as what started a problem is often not the same as what is keeping it going. ${ }^{31}$ In contrast to other psychotherapies, CBT is a short-term therapy, with treatment typically lasting six to ten sessions. Other characteristics of CBT which set it apart from other therapies include the collaborative nature and structured approach of CBT and asking clients to complete homework. Sessions involve assessment, collaborative goal setting, presenting and reviewing formulations (that is, working hypotheses about the client's problems), as well as receiving feedback. Homework is a key aspect of CBT, as performing tasks in between sessions enables the client to apply CBT techniques in a more natural environment and put what has been learnt in sessions into practice.

The efficacy of CBT for a range of psychological problems is now well established, most notably for depression and anxiety-related disorders (including phobias $^{32}$ ) but also for a diverse range of psychological disturbances. CBT has been reported to be "the psychological therapy with the most solid and wide evidence base for efficacy and effectiveness..33 Both cognitive and behavioural interventions have been shown to be successful in reducing dental anxiety and increase dental attendance. ${ }^{34-37}$ These positive effects have been shown to be maintained over time. ${ }^{38}$

A meta-analysis indicated that psychological interventions for dental phobia significantly reduced self-reported dental anxiety and increased dental attendance, with medium to large effect sizes. ${ }^{39}$ Approximately $77 \%$ of participants were seeing the dentist regularly after four years or more.

However the availability of CBT for dental phobia remains a significant barrier to its use in the UK. The Increasing Access to Psychological Therapies (IAPT) programme, while it has increased the availability of CBT services in primary care, is largely and appropriately focused on depression and general anxiety issues. We argue that the management of dental phobia requires close collaboration between trained CBT therapists and the dental team, since the behavioural tasks and homework tasks are likely to involve working around fears of dental equipment, the dental setting, chair etc. Furthermore the development of computer aided CBT should improve the availability of this form of intervention for dental phobics..$^{40,41}$

\section{CONCLUSION}

This article has proposed a model of dental anxiety management based on an initial assessment followed by proportionate interventions based on the level of dental anxiety identified. There are elements of the dental practice which can be modified to enable all patients to experience treatment more comfortably, whereas for those with moderate or severe levels of fear, more structured psychological and pharmacological interventions are required. In commissioning and developing dental 
services due consideration should be given to addressing the needs of all patients with dental anxiety.

1. Milgrom $P$, Newton $J T$, Boyle $C$, Heaton L J, Donaldson N. The effects of dental anxiety and irregular attendance on referral for dental treatment under sedation within the National Health Service in London. Community Dent Oral Epidemio 2010; 38: 453-459.

2. Coulthard $P$, Bridgman $C M$, Gough L, Longman $L$, Pretty I A, Jenner T. Estimating the need for dental sedation. 1. The Indicator of Sedation Need (IOSN) - a novel assessment tool. Br Dent J 2011; 211: E10.

3. Newton J T, Buck D J. Anxiety and pain measures in dentistry: a guide to their quality and application. J Am Dent Assoc 2000; 131: 1449-1457.

4. Buchanan $\mathrm{H}$. Acquisition and measurement of dental anxiety: a summary paper. Soc Sci Dent 2012; 2: 10-16.

5. Humphris G M, Morrison T, Lindsay S J. The Modified Dental Anxiety Scale: validation and United Kingdom norms. Community Dent Health 1995; 12: 143-150.

6. King K, Humphris G M. Evidence to confirm the cutoff for screening dental phobia using the Modified Dental Anxiety Scale. Soc Sci Dent 2010; 1: 21-28.

7. Humphris G M, Clarke H M, Freeman R. Does completing a dental anxiety questionnaire increase anxiety? A randomised controlled trial with adults in general dental practice. Br Dent J 2006; 201: 33-35.

8. Hull $\mathrm{P}$, Humphris G. Anxiety reduction via brie intervention in dentally anxious patients: a randomised controlled trial. Soc Sci Dent 2010; 1: 108-117

9. Wong $\mathrm{H}$ M, Humphris G M, Lee GT. Preliminary validation and reliability of the Modified Child Dental Anxiety Scale. Psychol Rep 1998; 83: 1179-1186.

10. Davey G C. Dental phobias and anxieties: evidence for conditioning processes in the acquisition and modulation of a learned fear. Behav Res Ther 1989; 27: $51-58$

11. Marinho V C, Higgins J P, Logan S, Sheiham A. Fluoride gels for preventing dental caries in children and adolescents. Cochrane Database Syst Rev 2002; CD002280.

12. Peretz B, Gluck G. Magic trick: a behavioural strategy for the management of strong-willed children. Int J Paediatr Dent 2005: 15: 429-436.

13. Greenbaum P E, Turner C, Cook E W 3rd, Melamed B G. Dentists' voice control: effects on children's disruptive and affective behaviour. Health Psychol 1990; 9: 546-558.
14. Ingersoll $B$ D, Nash D A, Blount R L, Gamber C. Distraction and contingent reinforcement with pediatric dental patients. ASDC J Dent Child 1984; 51: 203-207.

15. Filcheck H A, Allen K D, Ogren H, Darby J B, Holstein $B$, Hupp $S$. The use of choice-based distraction to decrease the distress of children at the dentist. Child Fam Behav Ther 2004; 26: 59-68.

16. Wardle J. Management of dental pain. York: Paper presented at British Psychological Society, 1982.

17. Pickrell J E, Heima M, Weinstein P et al. Using memory restructuring strategy to enhance dental behaviour. Int J Paediatr Dent 2007: 17: 439-448.

18. Shapiro M, Melmed R N, Sgan-Cohen H D, Eli I, Parush S. Behavioural and physiological effect of dental environment sensory adaptation on children's dental anxiety. Eur J Oral Sci 2007 . 155: 479-483.

19. Shapiro M, Sgan-Cohen H D, Parush S, Melmed R N Influence of adapted environment on the anxiety of medically treated children with developmenta disability. J Pediatr 2009; 154: 546-550.

20. Fox C, Newton J T. A controlled trial of the impact of exposure to positive images of dentistry on anticipatory dental fear in children. Community Dent Oral Epidemio/ 2006; 34: 455-459.

21. Richardson P H, Black N J, Justins D M, Watson $R J$. The use of stop signals to reduce the pain and distress of patients undergoing a stressful medical procedure: an exploratory clinical study. Br J Med Psychol 2009; 72: 397-405

22. Corah N L, Gale E N, Illig S J. The use of relaxation and distraction to reduce psychological stress during dental procedures. J Am Dent Assoc 1979. 98: 390-394.

23. Kritsidima M, Newton T, Asimakopoulou K. The effects of lavender scent on dental patient anxiety levels: a cluster randomised controlled trial. Community Dent Oral Epidemiol 2010; 38: 83-87.

24. Auerbach S M, Kendall P C, Cuttler H F, Levitt N R. Anxiety, locus of control, type of preparatory information, and adjustment to dental surgery. J Consult Clin Psychol 1976; 44: 809-818.

25. Forbes M D, Boyle C A, Newton T. Acceptability of behaviour therapy for dental phobia. Community Dent Oral Epidemiol 2012; 40: 1-7.

26. Newton J T, Naidu R, Sturmey P. The acceptability of the use of sedation in the management of dental anxiety in children: views of dental students. Eur $J$ Dent Educ 2003; 7: 72-76.

27. Atkinson R L, Atkinson R C, Smith E E, Bem D J Nolen-Hoeksema S. Hilgard's introduction to psychology. 12th ed. Orlando: Harcourt Brace College Publishers, 1996

28. Beck A T. Cognitive therapy and the emotional disorders. Michigan: International Universities Press, 1976.

29. Thorpe S J, Salkovskis P M. Phobic beliefs; do cognitive factors play a role in specific phobias? Behav Res Ther 1995; 33: 805-816.

30. Kirk J, Rouf K. Specific phobias. In Bennett-Levy J, Butler G, Fennell M, Hackmann A, Mueller M, Westbrook D (eds) Oxford guide to behavioural experiments in cognitive therapy. Oxford: Oxford University Press, 2007.

31. Eagle A, Worrel M. Cognitive behaviour therapy. In Ayers S, Baum A, McManus C et al. (eds) Cambridge handbook of psychology, health and medicine. 2nd ed. pp 340-343. Cambridge: Cambridge University Press, 2007

32. National Institute for Clinical Excellence. Anxiety: management of anxiety (panic disorder, with or without agoraphobia, and generalised anxiety disorder) in adults in primary, secondary and community care. London: NICE, 2004

33. Kennerley $\mathrm{H}$, Westbrook D, Kirk J. An introduction to cognitive behavioural therapy: skills and applications. London: Sage 2007.

34. de Jongh $A$, Muris $P$, ter Horst $G$, van Zuuren F J Schoenmakers N, Makkes P. One-session cognitive treatment of dental phobia: preparing dental phobics for treatment by restructuring negative cognitions. Behav Res Ther 1995; 33: 947-954.

35. Berggren U, Hakeberg M, Carlsson S G. Relaxation vs. cognitively oriented therapies for dental fear. J Dent Res 2000; 79: 1645-1651.

36. Willumsen T, Vassend O, Hoffart A. A comparison of cognitive therapy, applied relaxation and nitrous oxide sedation in the treatment of dental fear. Acto Odontol Scand 2001; 59: 290-296.

37. Willumsen T, Vassend O, Hoffart A. One-year followup of patients treated for dental fear: effects of cognitive therapy, applied relaxation and nitrous oxide. Acta Odontol Scand 2001; 59: 335-340.

38. Willumsen $T$, Vassend 0 . Effects of cognitive therapy, applied relaxation and nitrous oxide sedation. A five-year follow-up study of patients treated for dental fear Acta Odontol Scand 2003; 61: 93-99.

39. Kvale G, Berggren U, Milgrom P. Dental fear in adults: a meta-analysis of behavioural interventions. Community Dent Oral Epidemiol 2004; 32: 250-264.

40. Marks I M, Cavanagh K, Gega L. Hands-on help: computer-aided psychotherapy. (Maudsley Monograph 49). London: Psychology Press, 2007.

41. National Institute for Clinical Excellence. TA97 Computerised cognitive behaviour therapy for depression and anxiety: guidance. London: NICE, 2008. Online article available at http://www.nice org.uk/guidance/TA97/Guidance/doc (accessed August 2012) 